\title{
Effect of Heat Treatment on Tribological Characteristics of CuAl10Ni5Fe4 Nickel Aluminum Bronze
}

\author{
MUHAMMAD Kamran Yaseen ${ }^{a^{*}}$, MUHAMMAD Mansoor ${ }^{b}$, \\ HAIDER Ali Ansari ${ }^{c}$, SAJAWAL Hussain ${ }^{d}$ and SAHEED Khan ${ }^{e}$
}

Institute of Industrial Control Systems, P.O. Box 1398, Rawalpindi, Pakistan

akamran.met@gmail.com, bmalik01677@yahoo.com, chaider_ansari@live.com, dsajawalhussain09@gmail.com, 'shaheed_pe@hotmail.com

Keywords: Aluminum Bronze, Dry Wear, Alpha Phase, Kappa, Beta, Adhesive Wear, Coefficient of Friction, Coefficient of Wear.

\begin{abstract}
Al bronzes are used for relatively high-wear applications, besides appreciable mechanical and corrosion properties. In present work, the effect of different heat treatment processes on the tribological characteristics of $\mathrm{Ni}-\mathrm{Al}$ bronze has been studied. The Ni-Al bronze samples taken from hot-forged bar, were heated at $930^{\circ} \mathrm{C}$ and cooled down to room temperature. The effects of cooling rate on microstructure were studied and co-related with tribological characteristics. The formation and nucleation of various phases due to the thermal treatments were observed using optical microscopy. The wear behavior was studied using ball-on-disk arrangement with 100Cr6 ball and $\mathrm{Ni}$-Al bronze sample as disk. The characteristics and mechanism of wear tracks morphology were studied using scanning electron microscope. It was observed that the furnace cooled sample exhibited better tribological characteristics as compared to the samples treated at different parameters.
\end{abstract}

\section{Introduction}

Copper alloys containing 9-12\% aluminum and up to $6 \%$ of iron and nickel each, represent an important group of commercial aluminum bronzes. They also contain a small amount of manganese. Along with high strength, superior aesthetics and good damping capacity (twice than that of steel), these alloys exhibit good resistance to corrosion and wear, which make them one of the most useful engineering materials in their class. Al-bronzes find their widespread applications in aerospace, marine, architecture and oil sectors, which include landing gear bushes and bearings of aircrafts, non-sparking tools in oils and gas industries and pleasing facades in architecture, etc. [1].

$\mathrm{CuAl10Ni5Fe} 4$ aluminum bronze has a two-phase microstructure; poor formability $\alpha$ phase and excellent hot formability $\beta$ phase. The alloy has poor formability at room temperature due to rapid work hardening but shows good hot formability in $\alpha+\beta$ region. The alloy could be hot-worked between 700 to $900{ }^{\circ} \mathrm{C}[2,3]$. The $\alpha$ phase is a copper rich stable solid solution having FCC structure which gives ductility to the alloy, whereas the $\beta$ phase is an intermediate solid solution having $\mathrm{BCC}$ structure, which undergoes martensitic transformation upon rapid cooling from 1010 to $700{ }^{\circ} \mathrm{C}$. This martensitic $\beta$ phase has HCP structure and seems black upon etching. Tempering of $\beta$ results in dissociation of martensitic $\beta$ into very fine mass of $\alpha$ and $\kappa_{\mathrm{III}}$. In addition to $\alpha$ and $\beta$ and $\beta$, phases, various other inter-metallic kappa phases $(\kappa)$ formed in microstructure at various temperatures. These kappa inter-metallic phases are $\kappa_{\mathrm{i}}, \kappa_{\mathrm{ii}}, \kappa_{\mathrm{iii}}, \kappa_{\mathrm{iv}}$ and $\kappa_{\mathrm{v}}$ with different chemical compositions, shapes and properties. The $\kappa_{\mathrm{i}} \kappa_{\mathrm{ii}}$ and $\kappa_{\mathrm{iv}}$ phases are based on $\mathrm{Fe}_{3} \mathrm{Cl}$ crystal structure with $\mathrm{DO}_{3}$ space group, whereas, $\kappa_{\mathrm{iii}}$ and $\kappa_{\mathrm{v}}$ are based on NiAl crystal structure with $\mathrm{B} 2$ space group. The morphology each phase in the alloy is shown schematically in Fig. 1 [4-7].

Depending upon the application, $\mathrm{CuAl10Ni5Fe} 4$ alloy may undergo various heat treatments including annealing, quenching from $\alpha+\beta$ region or aging to acquire different levels of hardness and microstructures. The relative quantities of various phases and grain size corresponding to specific heat treatment parameters can influence the wear properties of the alloy. Unfortunately, the heat treatment parameters which gives best wear properties have not been determined yet. In current 
study, the hot forged (at $950^{\circ} \mathrm{C}$ ) specimens were heated to $930{ }^{\circ} \mathrm{C}$ and subjected to different cooling cycle namely furnace cooling, air cooling, water quenching and aging at $300{ }^{\circ} \mathrm{C}$. The microstructure, relative percentages of $\alpha$ and $\beta$ phases and hardness of samples including individual phases were studied and correlated with wear test results.

The severity of wear of samples is described by their wear rate and coefficient of friction. The relationship of parameters and results of wear testing were described by coefficient of wear in Archard equation.

$$
\mathrm{Q}=\mathrm{KW} / \mathrm{H} \text {. }
$$

Here, ' $\mathrm{Q}$ ' is wear rate expressed as volume loss per unit sliding distance, ' $\mathrm{W}$ ' is applied load in newtons $(\mathrm{N})$, ' $\mathrm{H}$ ' is hardness of sample on the Brinell scale $(\mathrm{HB})$ and ' $\mathrm{K}$ ' is wear coefficient. ' $\mathrm{K}$ ' is an integral parameter in this equation as it represents the severity of wear and is always less than unity. It involves all basic parameters which effect severity of wear [10].

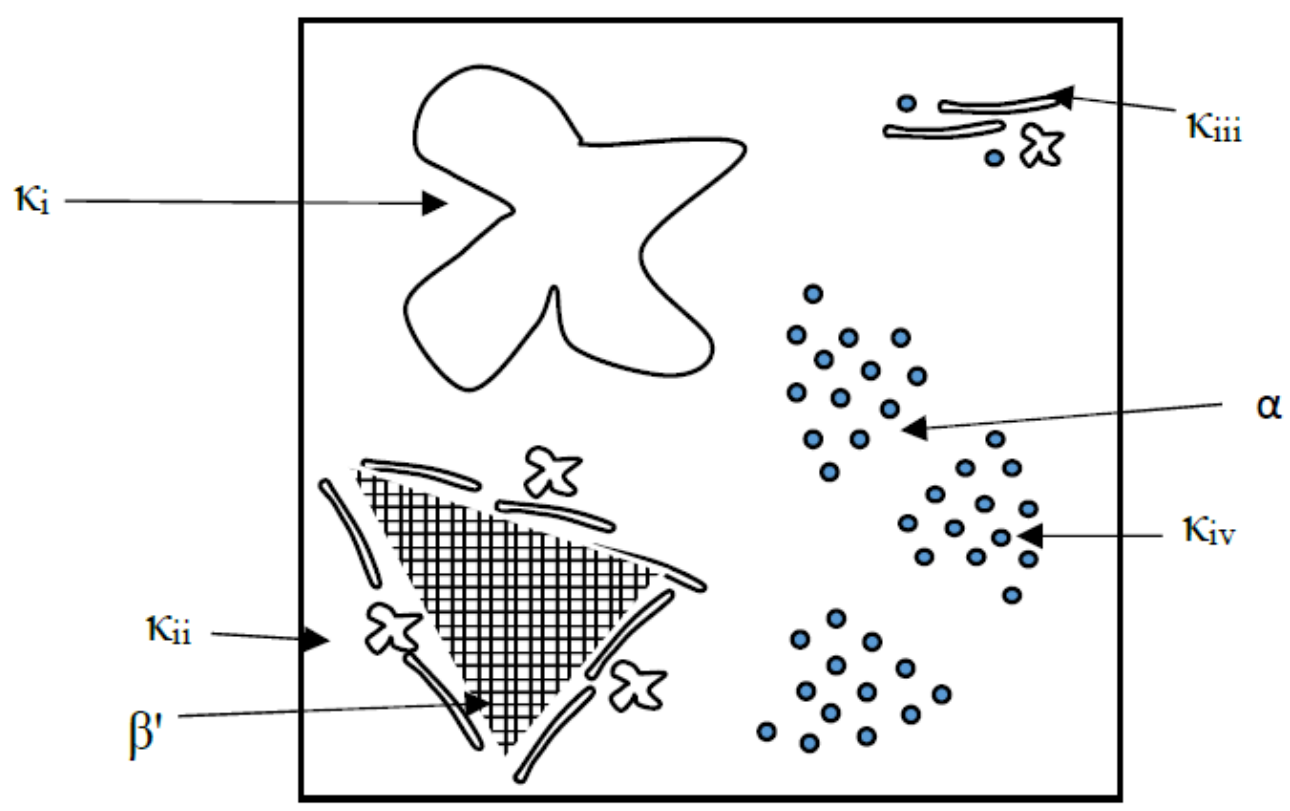

Fig. 1. Schematic representations of the various phases in a type 80-10-5-5 cast aluminum bronze.

\section{Experimental}

Four, disc shape specimens ( $8 \mathrm{~mm}$ thick), were sectioned in transverse direction from a hotforged bar having $30 \mathrm{~mm}$ diameter and were used during the present work. The aluminum bronze (CuAl10Ni5Fe4, UNS C63200) had the nominal composition of 9.5\% Al, 5.2\% Ni and 4.9\% Fe. The discs were heated in electric furnace at $930{ }^{\circ} \mathrm{C}$ for 30 minute. $1^{\text {st }}$ disk was allowed to cool in the furnace, $2^{\text {nd }}$ disk was air cooled and $3^{\text {rd }}$ disk was quenched in water followed by aging at $300{ }^{\circ} \mathrm{C} .4^{\text {th }}$ disk was not heat treated and used in hot-forged condition (hot forged at $950{ }^{\circ} \mathrm{C}$ followed by air cool) in further experiments. All the disks were ground and polished up to $0.05 \mu \mathrm{m}$ using alumina paste, etched in Kroll's reagent and observed using optical microscope. Grain size and relative percentage of individual phases were also determined using Olympus-Stream Motion software. The polished disks were subjected to Brinell hardness testing and micro-Vickers hardness testing to determine the hardness of bulk material and individual phases present in the microstructure, respectively. The surface roughness of polished samples was measured with surface profilometer. The weight of disks was measured using electronic balance, having an accuracy of up to four decimals, before and after the test. The tribological characteristics of the samples were determined with ball-on-disk setup using tribometer of CSM Instruments. A ball of 100Cr6 (AISI 51200) bearing steel, having $5 \mathrm{~mm}$ diameter was used. The parameters of all test performed are given in Table 1. Furthermore, the wear tracks of all samples were observed using stereo microscope, optical microscope and scanning electron microscope. The resulting features were correlated with the 
microstructure of samples and their corresponding mechanism of wear. The wear rate was determined by weight loss method using following formula:

Wear rate $=\frac{V}{L F}$

where, ' $\mathrm{V}$ ' indicates the volume of wear debris produced in $\mathrm{mm}^{3}$, ' $\mathrm{L}$ ' is the sliding distance in meters, and ' $\mathrm{F}$ ' is the normal load applied during test in newtons $(\mathrm{N})$. The results were discussed using wear rate, coefficient of friction and wear coefficient ' $\mathrm{K}$ ' of Archard equation.

Table 1. Parameters of Wear Test.

\begin{tabular}{|c|c|}
\hline Parameters & Values \\
\hline Normal Load & $10 \mathrm{~N}$ \\
\hline Sliding Distance & $50 \mathrm{~m}$ \\
\hline Travelling Speed & $10 \mathrm{~cm} / \mathrm{s}$ \\
\hline Temperature & $26^{\circ} \mathrm{C}$ \\
\hline
\end{tabular}

\section{Results and Discussion}

Microstructure and Hardness. The polished samples were etched with Kroll's reagent and observed using optical microscope. The microstructures of all samples: hot forged, furnace cooled, air cooled, quenched and aged at $300{ }^{\circ} \mathrm{C}$, are given in Fig. 2. The microstructure of hot forged samples consisted of $\beta+\kappa$ matrix having areas of $\alpha$. The micro hardness of the matrix was about $290 \mathrm{HV}$. Due to very fine grain size and non-uniform distribution of $\alpha$ and $\beta$, their grain size and area fraction could not be determined. The microstructure of furnace cooled sample from $930{ }^{\circ} \mathrm{C}$ contained $\alpha$ grains having $35 \mu \mathrm{m}$ average grain size with $\kappa_{\text {II }}$ precipitates, and non-equilibrium needle like $\beta$ ' phase. The micro hardness of $\alpha$ phase was $130 \mathrm{HV}$ as $\kappa_{\text {II }}$ precipitates were present within the $\alpha$-grains. The micro-hardness of dissociated $\beta$ was $190 \mathrm{HV}$ with area fraction of about $37 \%$. The sample cooled in air from $930{ }^{\circ} \mathrm{C}$ was comprised of white grains of $\alpha$ phase having $32 \mu \mathrm{m}$ average grain size and fine $\kappa_{\text {II }}$ precipitates. Due to relatively faster cooling than the furnace cooled sample, the proportion of the $\beta$ ' was high at the expense of the proportion of $\alpha$ phase. Moreover, a small fraction of $\beta$ phase was also retained in the microstructure which was darker in color as compared to $\beta$ ' phase. The micro-hardness of $\alpha$ phase was $110 \mathrm{HV}$ with area fraction of almost $61 \%$. The micro-hardness of $\beta$ ' was $210 \mathrm{HV}$ with area fraction of $39 \%$ of the microstructure. The quenched and aged sample had white $\alpha$ grains with $\kappa_{\text {II }}$ phase near grain boundaries, martensitic $\beta^{\prime}$ phase with $\kappa_{\mathrm{IV}}$ precipitates which provided hardness to the material. The micro-hardness of phase $\alpha$ and $\beta$ ' were $140 \mathrm{HV}$ and $410 \mathrm{HV}$, respectively. The $\alpha$-phase comprised almost $43 \%$ area fraction of the micro-structure and rest was $\beta$ '. The grain size, area percentage and hardness of samples are given in Table 2, and Table 3.

Table 2. Grain Size and Relative percentage of phases

\begin{tabular}{c|c|c|c}
\hline Sample & Grain Size of $\boldsymbol{\alpha}[\boldsymbol{\mu m}]$ & Percentage of $\boldsymbol{\alpha}$ & Percentage of $\boldsymbol{\beta}$ \\
\hline Hot forged & - & - & - \\
\hline Furnace cooled & 35 & 63 & 37 \\
\hline Air cooled & 32 & 61 & 39 \\
\hline $\begin{array}{c}\text { Quenched + Aged at } \\
300{ }^{\circ} \mathrm{C}\end{array}$ & 29 & 43 & 57 \\
\hline
\end{tabular}

Wear Testing. The results of tribological measurements are given in Fig. 3. The surface roughness $\left(R_{A}\right.$ value) of all the test specimens was in the range of $0.063 \pm 0.015 \mu \mathrm{m}$. The values of coefficient of friction, weight loss, wear rate and coefficient of wear along with parameters are given in Table 4 and graphical of wear test results are given in Fig. 3. 

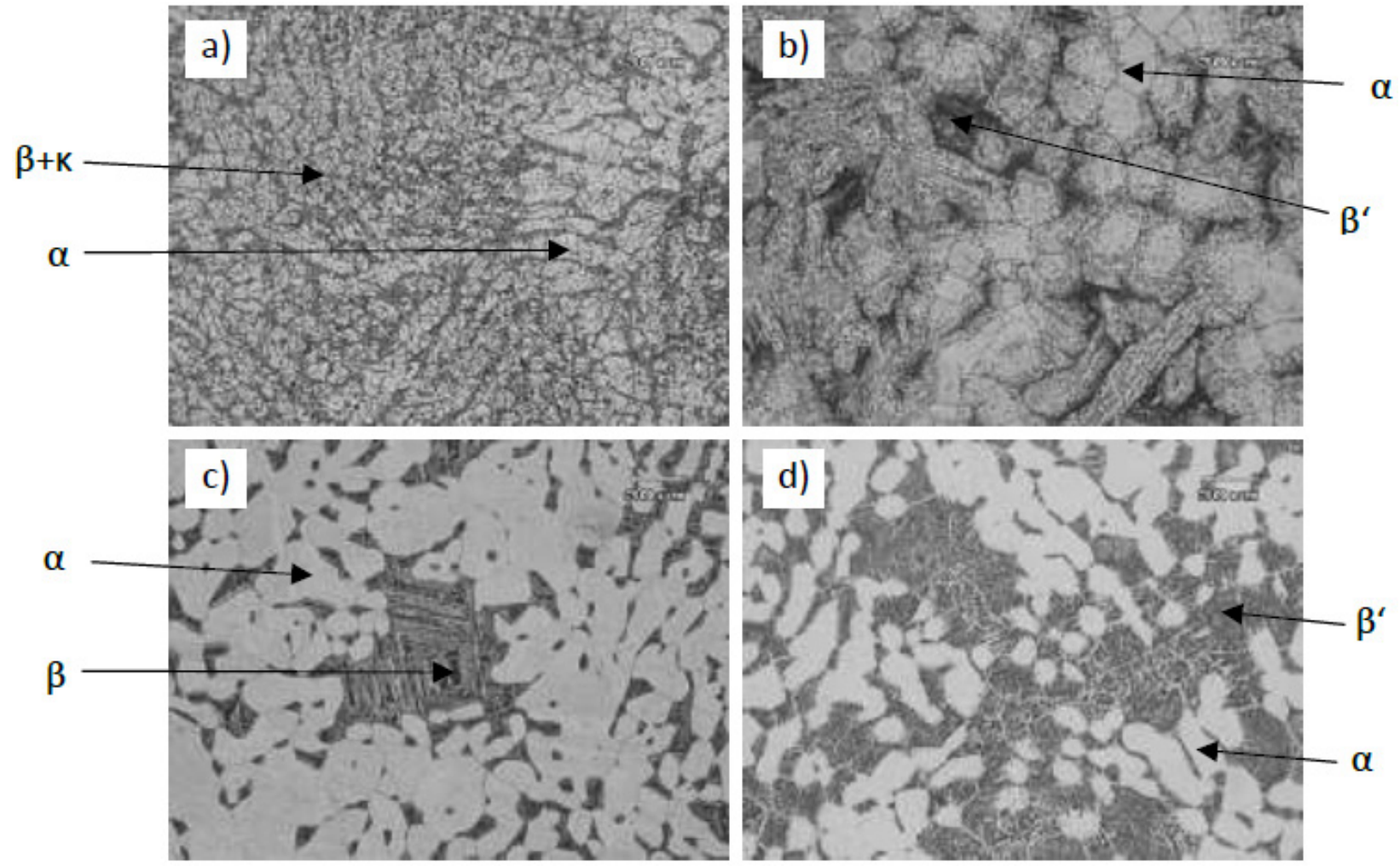

Fig. 2. Micrographs of Al-Bronze (a) hot forged at $950^{\circ} \mathrm{C}$, (b) furnace cooled, (c) air cooled and (d) quenched and aged at $300{ }^{\circ} \mathrm{C}$.
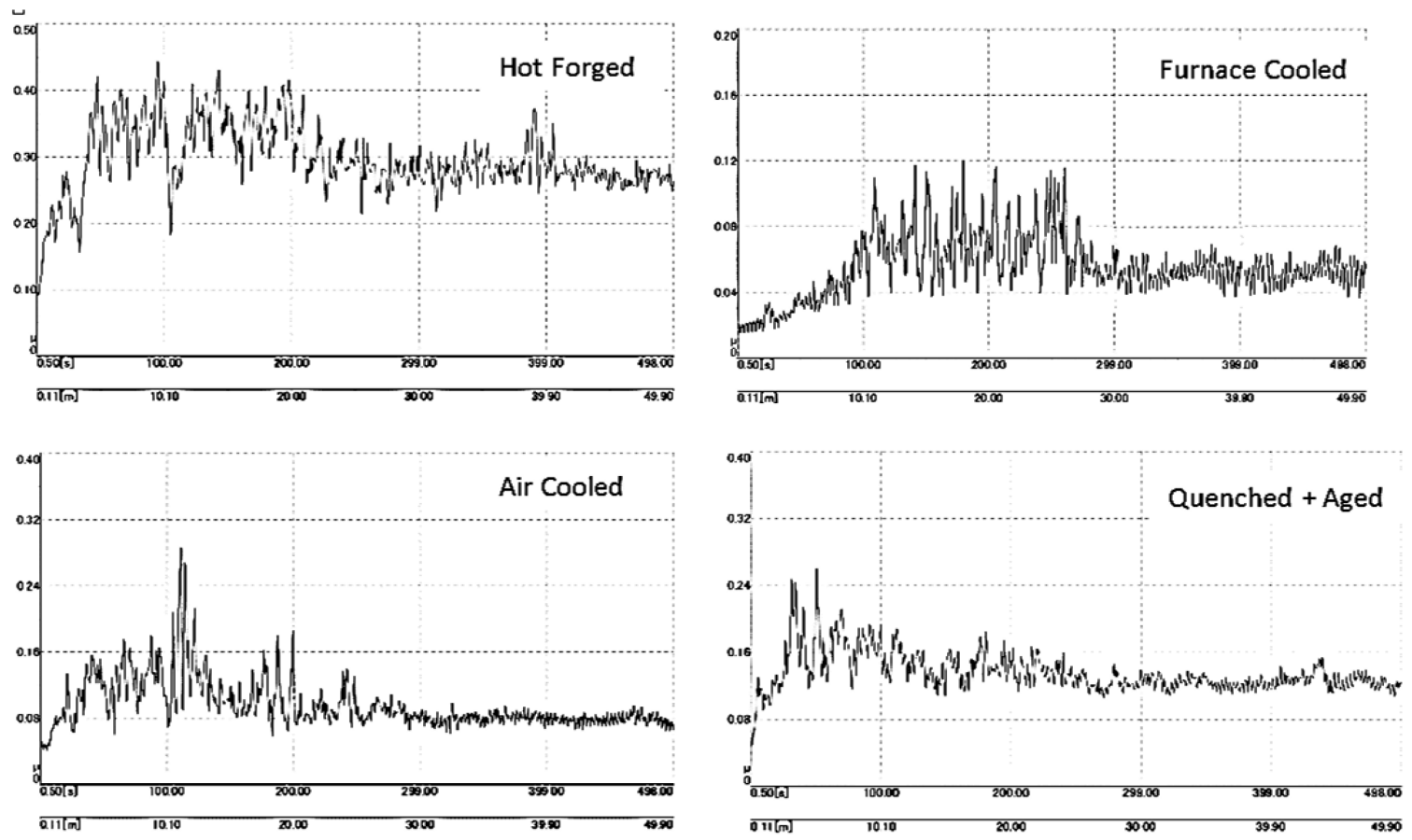

Fig. 3. Wear behavior of various test specimens showing coefficient of friction $(\mu)$ against time and sliding distance.

Table 3. Hardness of Bulk material and individual phases.

\begin{tabular}{c|c|c|c}
\hline Sample & $\begin{array}{c}\text { Bulk Hardness } \\
(\mathbf{H B})\end{array}$ & $\begin{array}{c}\text { Micro Hardness of } \\
\boldsymbol{\alpha} \text { (HV 25 gf) }\end{array}$ & $\begin{array}{c}\text { Micro hardness of } \\
\boldsymbol{\beta} \text { ( } \mathbf{\text { (HV 25gf) }}\end{array}$ \\
\hline Hot forged & 211 & - & 290 \\
\hline Furnace cooled & 184 & 130 & 190 \\
\hline Air cooled & 221 & 110 & 210 \\
\hline Quenched + Aged at $300^{\circ} \mathrm{C}$ & 311 & 140 & 410 \\
\hline
\end{tabular}


Table 4. Results of Wear testing of samples.

\begin{tabular}{c|c|c|c|c|c}
\hline Sample & $\begin{array}{c}\text { Co. of Friction } \\
(\boldsymbol{\mu})\end{array}$ & $\begin{array}{c}\text { Weight loss } \\
(\mathbf{g})\end{array}$ & $\begin{array}{c}\text { Volume loss } \\
\left(\mathbf{m m}^{\mathbf{3}}\right)\end{array}$ & $\begin{array}{c}\text { Wear Rate } \\
\left(\mathbf{m m}^{3} \mathbf{N}^{-1} \mathbf{m}^{-1}\right)\end{array}$ & $\mathbf{K}$ \\
\hline Hot Forged & 0.27 & 0.0026 & 0.314 & 0.0012545 & $2.65 \times 10^{-2}$ \\
\hline Furnace Cooled & 0.056 & 0.0010 & 0.121 & 0.0004825 & $8.88 \times 10^{-3}$ \\
\hline Air Cooled & 0.08 & 0.0028 & 0.338 & 0.0013510 & $2.99 \times 10^{-2}$ \\
\hline $\begin{array}{c}\text { Quenched + } \\
\text { Aged at } 300^{\circ} \mathrm{C}\end{array}$ & 0.13 & 0.0013 & 0.157 & 0.0006273 & $1.95 \times 10^{-2}$ \\
\hline
\end{tabular}

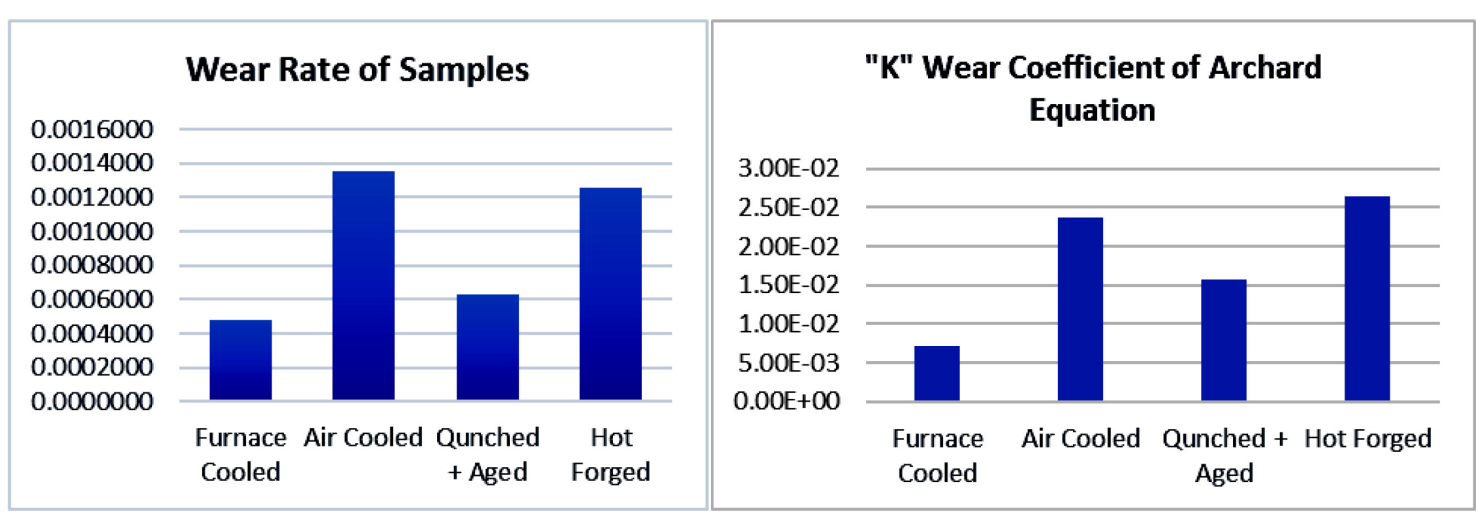

Fig. 4. Graphical presentation of (a) wear rate and (b) ' $K$ ', wear coefficient of samples.

Wear rate of all samples was determined according to ASTM G-99 04 [11]. Results obtained by specific set of parameters mentioned earlier revealed that among four samples; furnace cooled sample showed best tribological characteristics.

Scanning Electron Microscopy. Wear scar of each sample was studied using scanning electron microscope, Fig. 4. The different heat treatments given to the alloy had influenced the wear mechanisms being operative during the course of test. Very similar wear features were observed associated the wear scar of air cooled and as forged samples. Deep ploughing marks along with patches of adherent material were present on scars of both types of heat treated samples (Fig.4a, c). The edges of adherent material were cracked as can be seen in high magnification images (Fig. 4 b, d). The mechanism of wear in both samples could be related to their microstructure. As both samples comprise appreciable amount of soft and easily deformable FCC $\alpha$ phase, which could be the cause of ploughing marks in wear scars of both samples. Hard $\beta$ phase and $\kappa$ precipitates become embedded in soft $\alpha$ phase and become adherent with the wear track. The cracking of edges of the adherent material might be due to strain hardening of embedded material in $\alpha$ matrix.

In case of quenched and aged heat treated sample, the wear scar was free of ploughing marks, instead very fine size particles were present throughout in the wear scar (Fig. 4e). At higher magnification, these material particles were found adherent to the surface of the materials, the edges of which were observed disintegrated (Fig.4f). Low percentage of $\alpha$ phase and very hard $\beta$ ' along with $\kappa_{I V}$ are the cause of this mechanism of wear in quenched and aged sample. The hard particles of $\beta$ ' could not fully embedded in less amount of $\alpha$ phase and dispersed throughout the wear scar. Contrarily to quenched and aged samples, furnace cooled sample showed totally different mechanism as ploughing marks were present at the wear scar with the absence of any free particle or patch of loosely bound adherent material. Instead, layers of uniformly adherent material were observed at high magnification with smooth edges. No sign of strain hardening was observed in furnace cooled samples. This gross change in wear mechanism could be related to its microstructure in which almost $67 \%$ soft FCC $\alpha$ phase was present. On the other hand, the amount of $\beta$ ' phase and absence of martensitic $\beta$ phase promoted adhesion of material. The relatively hard phase $\beta$ ' and $\kappa$ precipitates become completely embedded in the $\alpha$ matrix and showed least resistance against sliding motion, hence resulting in minimum coefficient of friction and wear rate. 

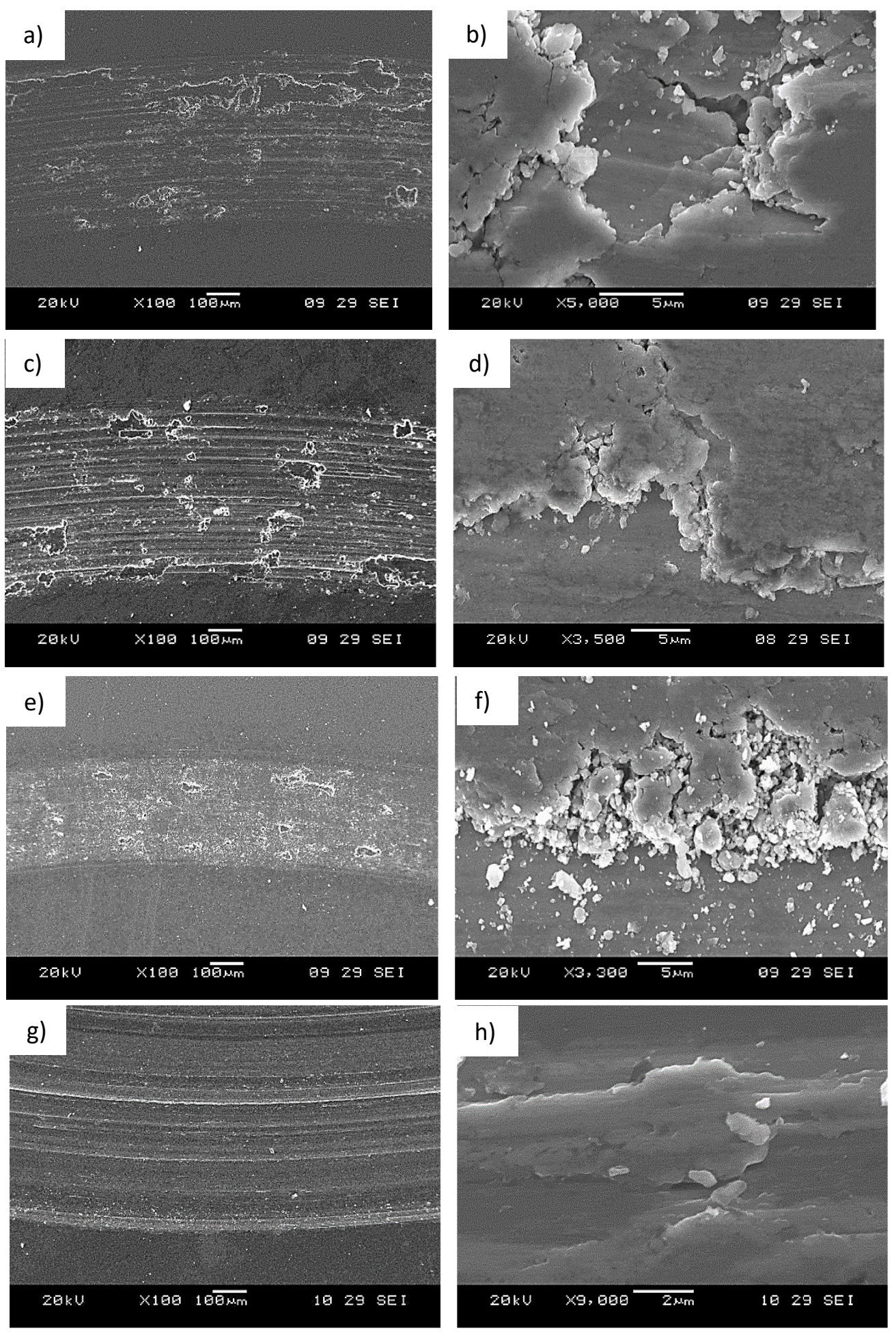

Fig. 4. SEM micrographs of wear tracts of samples showing wear mechanisms $(a, b)$ hot forged $(c, d)$ air cooled $(\mathrm{e}, \mathrm{f})$ quenched and aged at $300{ }^{\circ} \mathrm{C}$ and $(\mathrm{g}, \mathrm{h})$ furnace cooled at different magnifications.

The wear scar of furnace cooled sample was featured with ploughing marks (Fig. 4 g, h). On the contrary to other heat treated samples, the adherent patches of materials were not found in this case. This indicates that there was a gross change in the wear mechanism during the wear test of furnace cooled sample.

It is evident from the above results that changes in microstructure through controlled heat treatment has a pronounced effect on the wear characteristics of the aluminum bronze. The wear behavior which is characterized by coefficient of friction, wear rate and coefficient of wear could be related to the amount of phases present, their grain size and hardness of individual constituent. The 
bulk hardness alone is not a criterion to determine wear behavior of Al-bronze, rather specific amount of individual phases and their grain size along with bulk hardness give a combined response against wear behavior.

\section{Conclusions}

- The thermal treatments have significant influence on the microstructure of the alloy in which the volume fraction of $\alpha$ phase decreased with increasing the cooling rate.

- In addition to bulk hardness, relative amount and their grain size have substantial effect on wear mechanisms and wear characteristics of the alloy.

- Hot worked followed by furnace cool sample having $211 \mathrm{HB}$ hardness with $43 \% \alpha$ phase and $37 \% \beta$ ' phase showed relatively better tribological properties.

\section{References}

[1] I. Richardson, Guide to Nickel Aluminium Bronze for Engineers, Copper Development Association, 2016.

[2] ASM Handbook Volume, 2: properties and selection: nonferrous alloys and special-purpose materials, ASM international, (1990) 889-896.

[3] J.R. Davis, Copper and copper alloys, ASM international, 2001.

[4] H. Meigh, Cast and wrought aluminium bronzes: properties, processes and structure, Institute of Materials, 1 Carlton House Terrace, London, SW 1 Y 5 DB, UK, 2000. 404, (2000).

[5] M. Cook, E. Davis, W. Fentiman, Observations on the Structure and properties of Wrought Copper-Aluminium-Nickel-Iron Alloys, J. Inst. Met., 80 (1951) 419-429.

[6] P. Brezina, Heat treatment of complex aluminium bronzes, Internat. Met. Rev.,, 27 (1982) 77120.

[7] F. Hasan, A. Jahanafrooz, G. Lorimer, N. Ridley, The morphology, crystallography, and chemistry of phases in as-cast nickel-aluminum bronze, Metall. Trans. A, 13 (1982) 1337-1345.

[8] M.L.A. Brona, Influence of Heat Treatment on the Microstructure and Mechanical Properties of Aluminium Bronze, Mat. Technol., 48 (2014) 599-604.

[9] I. Hutchings, Tribology: Friction and Wear of Engineering Materials (Edward Arnold, London, 1992), Google Scholar, 20.

[10] Standard Test Method for Wear Testing with Pin-on-Disk Apparatus in: ASTM Standard G99 - 04, ASM, USA, 2004. 